\title{
Thermo-Economic Analysis of a Trigeneration HCPVT Power Plant
}

\author{
Angelos Selviaridis ${ }^{1,2}$, Brian R. Burg ${ }^{1}$, Anna Sophia Wallerand ${ }^{2}$, François \\ Marechal $^{2}$ and Bruno Michel ${ }^{1, \text { a) }}$
}

\author{
${ }^{1}$ IBM Research - Zurich, Säumerstrasse 4, 8803 Rüschlikon, Switzerland \\ ${ }^{2}$ École Polytechnique Fédéral de Lausanne (EPFL), STI-IGM-IPESE, Station 9, 1015 Lausanne, Switzerland \\ a)bmi@ zurich.ibm.com
}

\begin{abstract}
The increasing need for electricity and heat in a growing global economy must be combined with $\mathrm{CO}_{2}$ emissions reduction, in order to limit the human influence on the environment. This calls for energy-efficient and costcompetitive renewable energy systems that are able to satisfy both pressing needs. A High-Concentration Photovoltaic Thermal (HCPVT) system is a cogeneration concept that shows promising potential in delivering electricity and heat in an efficient and cost-competitive manner. This study investigates the transient behavior of the HCPVT system and presents a thermo-economic analysis of a MW-scale trigeneration (electricity, heating and cooling) power plant. Transient simulations show a fast dynamic response of the system which results in short heat-up intervals, maximizing heat recuperation throughout the day. Despite suboptimal coupling between demand and supply, partial heat utilization throughout the year and low COP of commercially available devices for the conversion of heat into cooling, the thermoeconomic analysis shows promising economic behavior, with a levelized cost of electricity close to current retail prices.
\end{abstract}

\section{INTRODUCTION}

The increase of solar energy harvesting requires both cost-effective and energy-efficient systems, which are able to compete with fossil fuel based electricity and heat generation. The PV market is currently dominated by low-cost, low-efficiency PV cells. These technologies have succeeded in providing cost-competitive electricity derived from solar energy. The main drawbacks of these systems are large areas of deployment and low conversion efficiency (record lab efficiency of multi-Si PV cells is $20.4 \%$ [1] whereas of III-V multi-junction cells is $46 \%$ [2]). CPV technologies use concentrators and high-efficiency PV cells to reduce the areas of deployment and increase the efficiency of conversion. It is shown that CPV systems can be cost-competitive for locations with yearly Direct Normal Irradiance (DNI) values of $2000 \mathrm{kWh} / \mathrm{m}^{2} \mathrm{a}$ and above [2].

Solar thermal applications are another important contributor towards the increase of the solar energy fraction in the global energy mix. Solar thermal installed capacity in 2012 saved 24.5 million tons of oil and 79.1 million tons of $\mathrm{CO}_{2}$ emissions [3]. This figure shows a great potential towards a "greener" future. However domestic hot water applications still dominate this field (87\% of total installed capacity, 2012) [3], while other heat-based applications need further development to reveal their potential. Solar heat for space heating could reduce global $\mathrm{CO}_{2}$ emissions, since this is usually the largest consumer of energy in buildings [3]. Similarly, the deployment of solar cooling installations results in even larger electricity and $\mathrm{CO}_{2}$ emissions savings. Especially, large-scale deployment of such installations allows regions with high air-conditioning demand to lower peak electricity loads, thereby limiting the need for additional electricity generation and transmission capacity and allowing for capital expenditure savings [4].

The High-Concentration Photovoltaic Thermal (HCPVT) system combines the advantages of CPV and solar thermal technologies. The system targets concentrations of 2000 suns, higher than most conventional CPV systems. At such concentrations, it is important to efficiently cool the PV cells in order to ensure proper operation. The 
recovered heat is further utilized to increase the energy efficiency of the system. As a result, the HCPVT system is a co-generation concept of electricity and heat that promises an overall efficiency of $80 \%$ (25\% electricity and $55 \%$ heat). Its novelty relies on the use of high-end, high-efficiency $3 \mathrm{~J} \mathrm{PV} \mathrm{cells,} \mathrm{cheap} \mathrm{and} \mathrm{reliable} \mathrm{concentrator} \mathrm{optics}$ made of fiber-reinforced concrete and microchannel active water coolers for heat extraction. The heat, extracted at constant high temperatures $\left(85^{\circ} \mathrm{C}\right)$ can be directly used for space heating or through an adsorption chiller for space cooling.

The aim of this study is two-fold. First, a physical model of the HCPVT system is developed using the CARNOT Blockset of MATLAB/Simulink[5]. The model is built in order to investigate the transient response of the system in minutely resolution during the day, including the effects of fluctuations in irradiation and clouding. Second, a trigeneration HCPVT power plant for the location of Phoenix, AZ, U.S.A., is modeled based on the first model by using a process and energy system design platform (OSMOSE), developed at EPFL [6]. A thermo-economic analysis of the plant is performed, investigating the integration potential of the heat produced by the HCPVT into a district heating and cooling network, both from an energetic and an economical point of view.

\section{HIGH CONCENTRATION PHOTOVOLTAIC THERMAL SYSTEM}

The HCPVT system is made up by two major and distinct parts, the concentrator optics and the Multi-Cell Receiver (MCR) modules. The primary concentrator is a $40 \mathrm{~m}^{2}$ dish comprised of multi-elliptical facet mirrors, arranged in a special topology. Six identical and radially distributed facet arrays concentrate the solar irradiation on six MCRs. Secondary optics exist at the level of the MCRs, in order to improve concentration and homogeneity on the MCR area. Each MCR is composed of a $5 \times 5$ dense array of $3 \mathrm{~J}$ PV cells mounted on a very low thermal resistance microchannel water cooler. In absolute terms, $25 \%$ of the solar irradiation that is incident on the dish is converted into electricity and $55 \%$ of it is recuperated in form heat $\left(85^{\circ} \mathrm{C}\right)$. Most of the heat $(\sim 50 \%$ of the incident irradiation) is recuperated by the MCR coolers and an additional small amount ( $\sim 5 \%$ of the incident irradiation) is recuperated at the secondary optics of the system. That means that a total first law efficiency of the system of $80 \%$ is achieved [7].

\section{METHODOLOGY}

\section{Physical system model}

The physical model of the HCPVT system, designed in MATLAB/Simulink, aims at providing a better understanding of the transient behavior of the system and allows for obtaining the temperature enthalpy profile of heat during its operation. The model consists of two water loops connected with a heat exchanger (Fig. 1). The primary loop is responsible for extracting the heat from the MCRs and the secondary optics. The thermal behavior of the MCRs is modeled with a set of differential equations [8], taking into account the thermal mass of the receivers and the water inside them. After the MCRs the flow passes through the secondary optics cooler, in order to recuperate the additional amount of heat at that level. The loop also includes dynamic models of an expansion vessel, a heat exchanger, a pump, a cooling control unit and piping. The secondary loop includes an idealized thermal user, who is able to instantly recover the heat from the system.

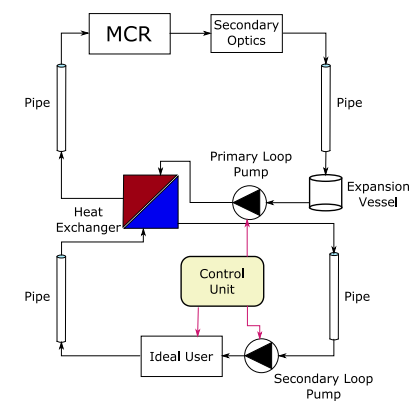

FIGURE 1. Schematic of the cooling loops of the HCPVT system. 
The system tracks the sun when the Direct Normal Irradiance (DNI) is higher than zero. At that time, the pump of the primary loop is switched on and operates at a constant mass flow rate, in order to ensure a high heat transfer coefficient within the MCRs. The user extracts as much heat as needed, in order to keep the inlet temperature of the MCRs at $85^{\circ} \mathrm{C}$. At the same time, the mass flow rate of the secondary loop is controlled in order to maintain a $5^{\circ} \mathrm{C}$ temperature difference between the low and high temperature of the secondary loop. During the heat-up phase in the morning, the secondary loop pump is switched on only when the desired temperature level is reached $\left(85^{\circ} \mathrm{C}\right.$ at the inlet of the MCRs). The outlet temperature of the MCRs varies between $85^{\circ} \mathrm{C}$ and $90^{\circ} \mathrm{C}$, depending on the DNI. The temperature of the PV cells (junction temperature) also varies and the control strategy ensures that it stays within the operational limits of the cells (below $100^{\circ} \mathrm{C}$ at all times). Finally, the heat exchanger is dimensioned in such a way that the high temperature of the secondary loop reaches $85^{\circ} \mathrm{C}$ for a low temperature of $80^{\circ} \mathrm{C}$.

\section{Thermo-economic analysis}

A thermo-economic analysis is performed in order to investigate the integration potential of the energy produced by the HCPVT system into a district heating and cooling network, both from an energetic and economical point of view. A trigeneration HCPVT power plant (Fig. 2a) is defined for this purpose. While the HCPVT systems produce electricity and heat directly, the cooling is produced by an adsorption chiller relying on the HCPV systems as heat source. The power plant also consists of daily thermal storage, a wet cooling tower, a back-up vapor compression chiller and a back-up natural gas burner. The wet cooling tower is responsible for rejecting the heat produced by the HCPVT, when there is no demand for it and for rejecting the heat from the two chillers. Electricity consumption of the cooling tower is assumed to be $2 \%$ of the thermal power rejected [8]. The back-up equipment covers the deficit of heating and cooling, when the heat produced by the HCPVT is insufficient. The power plant is located just outside Phoenix, AZ, U.S.A. and covers the cooling and heating demand of urban households, located $10 \mathrm{~km}$ away from the plant, throughout the year. The electricity generated is sold to the grid. At the same time, the power plant is able to import electricity from the grid, if needed.

The thermo-economic analysis is performed by applying an energy integration optimization methodology [9]. The optimization problem is expressed as a Mixed Integer Linear Programming (MILP) problem. The objective of the optimization is to identify the optimal size of the equipment needed (cooling tower, thermal storage, adsorption chiller, back-up chiller and burner) for the proper operation of a MW-scale trigeneration power plant and the covering of the demand of a fixed number of households targeting minimum operating cost. The energy integration is performed based on the "process" units' and "utilities" hot and cold streams and the streams' respective minimum temperature difference [9]. The model also includes an optimal predictive control algorithm that is used in order to manage the storage tank.

The applied methodology is performed in three steps (Fig. 2b). The OSMOSE platform [5] from EPFL is used as

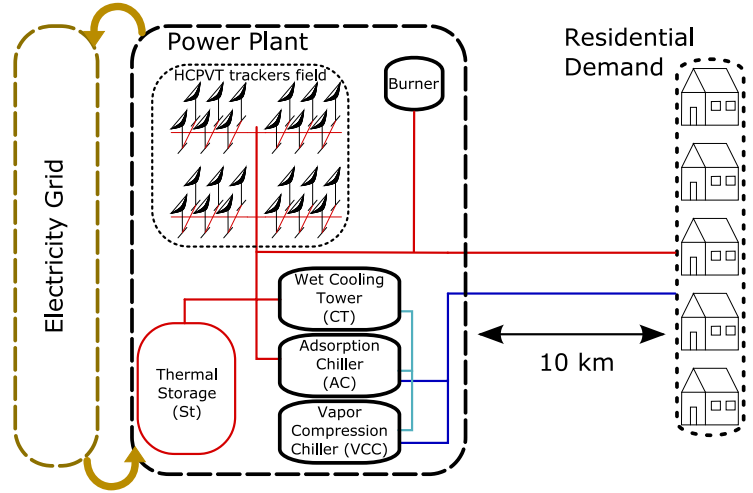

(a)
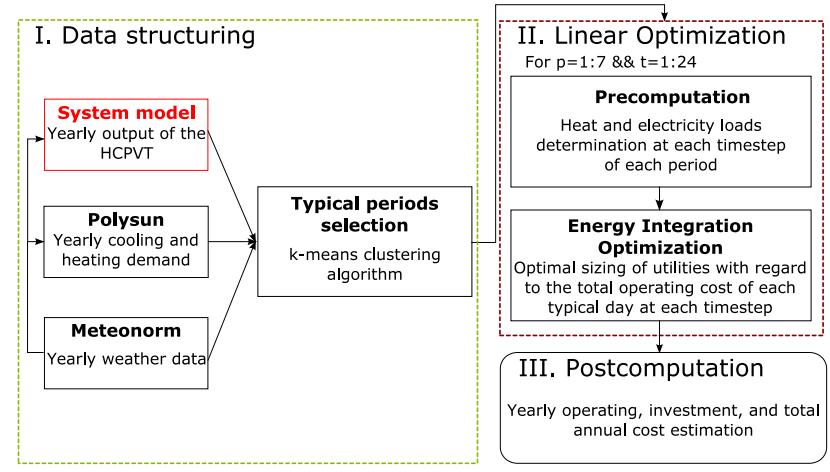

(b)

FIGURE 2. (a) Schematic of the trigeneration power plant. (b) Schematic of the methodology used for the thermo-economic analysis. 
the computational framework which links the different steps. Data structuring is the first step. The results from the physical system model are combined with simulations from the Polysun software [10] and weather data from the Meteonorm software [11] to determine the yearly cooling and heating demand. Seven typical days are selected, representing the availability of solar energy and the demand for heating and cooling throughout the year. The selection is performed with a k-means clustering algorithm [12]. The typical days include the seasonal and daily variations of all decision variables and are used in order to reduce the computational cost of optimization. The second step is the optimization phase, where the energy integration optimization problem is solved for each time step and every typical day. Finally, the results are post-processed in the post-computation phase, where the total annual cost is estimated and the thermal behavior of the system is evaluated.

Thermal storage plays an important role in the process of optimization. In the current study, a daily water thermal storage is assumed and modeled [13], with a temperature difference of $10^{\circ} \mathrm{C}$ between the top and the bottom of the storage tank $\left(85^{\circ} \mathrm{C}\right.$ to $\left.75^{\circ} \mathrm{C}\right)$. Furthermore, the cooling production is dependent on the availability of solar energy as well as the ambient (wet-bulb) temperature (and subsequently the cooling water temperature at the cooling tower) and the temperature of hot water entering the adsorption chiller. An explicit relation is defined as a function of chilled water, cooling water and hot water temperatures, in order to calculate the Coefficient of Performance (COP) of the chiller [8]. Chilled water is assumed to be produced at $7^{\circ} \mathrm{C}$ and the maximum COP of the chiller is around 0.6 for a cooling water temperature of $32^{\circ} \mathrm{C}$ (ambient temperature at $25^{\circ} \mathrm{C}$ ) and a hot water temperature of $80^{\circ} \mathrm{C}$. A similar relation is defined for the vapor compression chiller [8], the COP of which is between 4 and 5, also depending on the ambient (wet-bulb) temperature.

TABLE 1. Resources pricing. The prices were retrieved for March, 2014.

\begin{tabular}{lcc}
\hline \multicolumn{1}{c}{ Type } & Price & Unit \\
\hline Electricity (retail price) & $0.11[14]$ & $\$ / \mathrm{kWh}$ \\
Natural Gas & $0.03[15]$ & $\$ / \mathrm{kWh}$ \\
Water & $1.34[16]$ & $\$ / \mathrm{m}^{3}$ \\
\hline
\end{tabular}

The net annual income is calculated in order to quantify the economic performance of the plant. It is calculated by substracting the annual operating cost and the annualized investment cost from the yearly revenues. The operating cost consists of the expenses for electricity imported from the grid, natural gas and water. It is linearly dependent on their prices (Table 1). The investment cost of the system is calculated based on correlations found in the literature ([8], [17], [18]) and based on the size of each of the elements of the system. The annualized investment cost is determined by assuming a lifetime of 25 years for the plant and an interest rate of $8 \%$. The power plant gets revenues from selling electricity to the grid and heating and cooling to the households. The electricity selling price is assumed to be the same as the electricity buy price in Table 1 and the heating selling price is assumed to be the same as the natural gas price. For cooling, the price in $\$ / \mathrm{kWh}$ is assumed to be $1 / 4$ of the electricity price, assuming that the COP of a typical air conditioning machine is around 4. Energy prices are assumed to be constant throughout the lifetime of the plant.

\section{RESULTS AND DISCUSSION}

\section{Simulation of the HCPVT system for a clear sunny day}

A simulation of the physical model is performed for Phoenix, AZ, with weather data taken from the Meteonorm software [11] for July $1^{\text {st }}$ (Fig. 3). It is shown that the temperatures are stabilized around the set points set by the control system $\left(85^{\circ} \mathrm{C}\right.$ for the inlet temperature to the receiver $T_{\text {in }}$ and the high temperature of the secondary loop $\mathrm{T}_{\mathrm{sl}, \mathrm{hot}}, 80^{\circ} \mathrm{C}$ for the low temperature of the secondary loop $\mathrm{T}_{\mathrm{sl}, \text { cold }}$. The outlet temperature of the receiver $\mathrm{T}_{\text {out }}$ remains at around $90^{\circ} \mathrm{C}$, without getting closer to the boiling temperature of water. Finally, the junction temperature $\mathrm{T}_{\mathrm{j}}$ remains below $100^{\circ} \mathrm{C}$ and within the operational limits of the PV cells. The heat-up phase in the morning lasts about 12 minutes, highlighting the quick dynamic response of the system.

The electricity generated by the HCPVT system (Fig. 3b) reaches a peak of $10 \mathrm{~kW}$ for a DNI of $1000 \mathrm{~W} / \mathrm{m}^{2}$ and is around $8 \mathrm{~kW}$ for the peak hours of solar irradiation that day, when DNI is around $800 \mathrm{~W} / \mathrm{m}^{2}$. Electricity and heat are produced during a 12 hour period. The total energy that is incident on the dish for this day is $350.94 \mathrm{kWh}$, with 


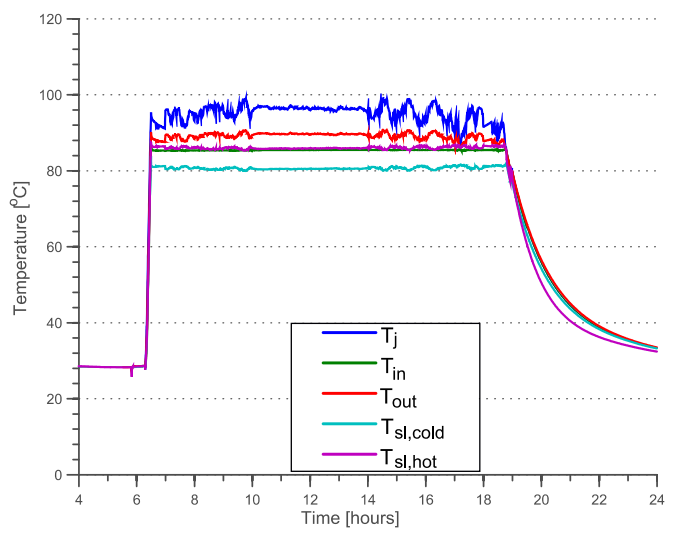

(a)

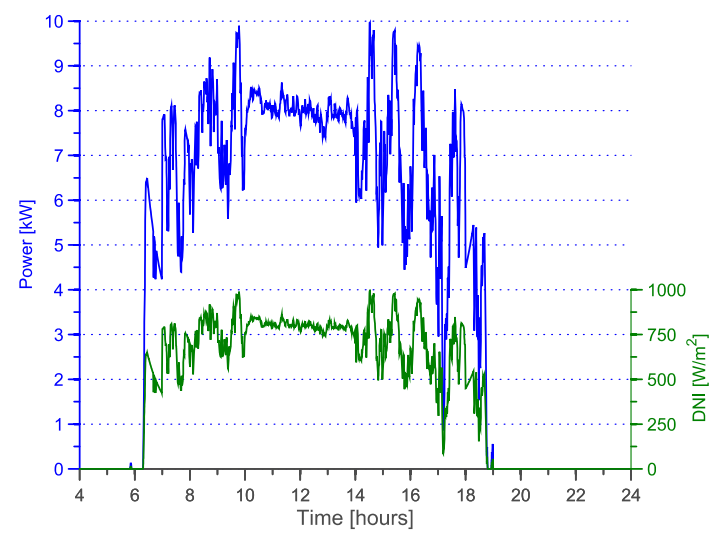

(b)

FIGURE 3. The behavior of the HCPVT system on a clear sunny day (July 1st) for the location of Phoenix, AZ, U.S.A. in terms of (a) temperatures and (b) electricity output. The temperatures are kept almost constant during the operation of the system throughout the day.

$25 \%$ being converted into electricity $(87.83 \mathrm{kWh})$ and $76 \%$ being converted into heat $(176.57 \mathrm{kWh})$. Only $4 \%$ of the incident radiation is used for the heat-up of the system. It should be underlined that the system power output is almost independent of the season and only dependent on DNI, since its operation is based on two-axis tracking.

\section{System integration}

Six different scenarios are evaluated for the system integration study, in order to determine the influence of demand size, supply size and the existence of storage on the energetic and economic performance of such a trigeneration plant (Table 2). Three main cases are examined. First, a $10 \mathrm{MW}_{\mathrm{el}}$ power plant (1000 HCPVT trackers, scenario A.1) is investigated, covering the demand of 500 houses. Second, an analogous analysis is carried out for a $5 \mathrm{MW}_{\text {el }}$ power plant (500 trackers, scenario A.2) covering the demand of 250 houses. Third, a "hybrid" case is analyzed, where a $5 \mathrm{MW}_{\text {el }}$ plant (scenario A.3) is supposed to cover the demand of 500 houses by additionally utilizing the back-up equipment substantially. Finally, all three cases are also evaluated when combined with daily thermal storage (scenarios B.1 to B.3). It is determined by the typical days selection algorithm that there are 178 days of the year with cooling demand, 22 days of the year with heating demand and 165 days (about 1/3 of the year), when there is neither heating nor cooling demand and the heat has to be rejected to the ambient.

\begin{tabular}{cccc}
\multicolumn{3}{c}{ TABLE 2. Selected scenarios to be investigated. } \\
\hline Scenario & Plant Size & Households supplied & Daily Thermal Storage \\
\hline A.1 & $10 \mathrm{MW}_{\mathrm{el}}$ & 500 & No \\
A.2 & $5 \mathrm{MW}_{\mathrm{el}}$ & 250 & No \\
A. 3 & $5 \mathrm{MW}_{\mathrm{el}}$ & 500 & No \\
B.1 & $10 \mathrm{MW}_{\mathrm{el}}$ & 500 & Yes \\
B. 2 & $5 \mathrm{MW}_{\mathrm{el}}$ & 250 & Yes \\
B.3 & $5 \mathrm{MW}_{\mathrm{el}}$ & 500 & Yes \\
\hline
\end{tabular}

The importance of thermal storage is identified when comparing the energy integration profiles for scenarios A.1 and B.1 (Fig. 4). For scenario A.1, it is shown that between 10:00 and 18:00 the heat produced by the HCPVT $\left(\mathrm{Q}_{\text {нсрут }}\right)$ is not enough to operate the adsorption chiller $\left(\mathrm{Q}_{\mathrm{hw}, \mathrm{AC}}\right)$ and cover the peak cooling demand of the households $\left(\mathrm{Q}_{\mathrm{chw}, \mathrm{AC}} \neq \mathrm{Q}_{\mathrm{demand}}\right)$. At that time the back-up vapor compression chiller $\left(\mathrm{Q}_{\mathrm{vCC}}\right)$ is utilized to cover the cooling load deficit. The back-up chiller also operates after sunset to cover the cooling demand in the evening. In contrast, during morning and late afternoon hours, there is a surplus of heat that is not utilized and is rejected by the cooling tower $\left(\mathrm{Q}_{\mathrm{CT}}\right)$. This inefficient behavior is improved through the use of the thermal storage in scenario B.1. The thermal storage is charged $\left(\mathrm{QSt}^{+}\right)$when there is a surplus of heat and discharged $\left(\mathrm{Qst}_{\mathrm{st}}{ }^{-}\right)$when there is a deficit of 


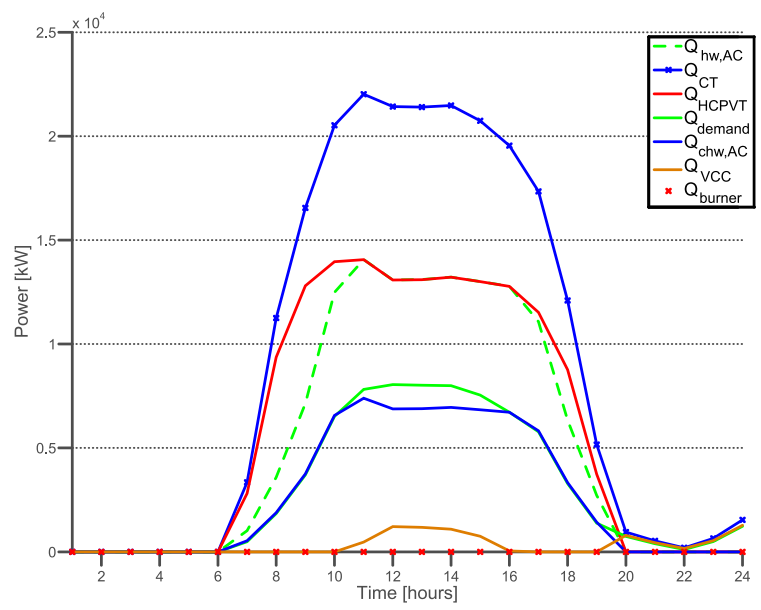

(a)

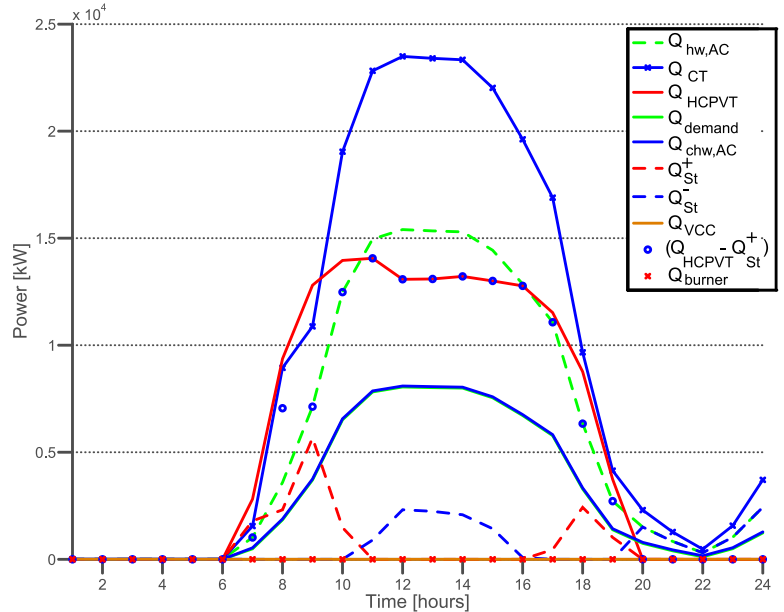

(b)

FIGURE 4. Energy integration profiles for scenario (a) A.1 and (b) B.1 for a typical day with cooling demand. Thermal storage is used in scenario B.1, so that peak cooling loads during morning and afternoon hours as well as evening cooling loads are covered by the adsorption chiller.

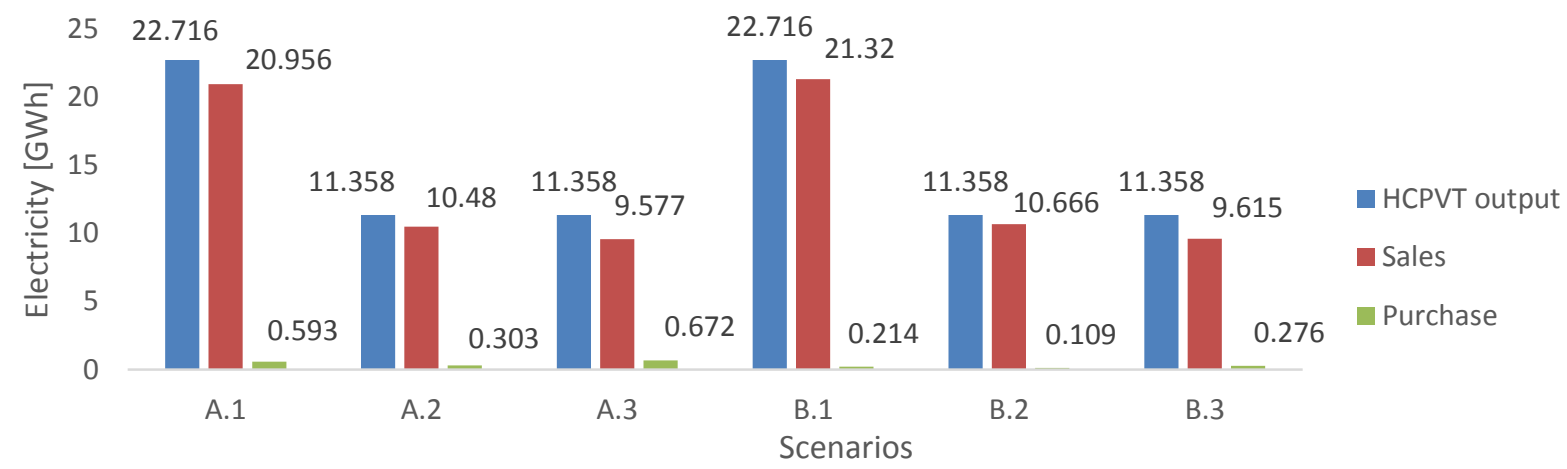

FIGURE 5. Yearly electricity production, sales and purchase for each scenario. The maximum yearly electricity sales are achieved for scenario B.1

heat to drive the adsorption chiller. As a result, there is no need to operate the back-up chiller and electricity savings are achieved.

By summarizing the energetic evaluation of the six scenarios (Fig. 5), it is shown that scenarios B.1and B.2 succeed in having the highest electricity sales in analogy to the size of the field. This is due to the fact that the utilization of storage leads to electricity savings for both scenarios. The "hybrid" cases (scenarios A.3 and B.3) are less efficient in terms of electricity balance, since they need more imported electricity (purchase) in order to cover the demand but they result in larger sales of heating and cooling energy.

\section{Cost analysis}

It is calculated that all six scenarios have a negative net annual income during the lifetime of 25 years and assuming an interest rate of $8 \%$. In a next step, the Levelized Cost of Electricity (LCOE) in $\mathrm{c} \$ / \mathrm{kWh}$ is determined for each scenario (Fig. 6). Scenario B.1 is identified as the one with the lowest value of $12.6 \mathrm{c} \$ / \mathrm{kWh}$. This value is very close to the electricity price (both purchase and selling price) used in the calculations, which is $11 \mathrm{c} \$ / \mathrm{kWh}$. Scenario B.1 has the best economic performance for two reasons. First, compared to scenario A.1, the existence of storage leads to more efficient energy consumption within the plant, thus higher amounts of electricity available for sale. Second, a larger-scale power plant performs better in terms of cost, since it is assumed that there is a small price drop in the investment cost per tracker for the larger plant. 


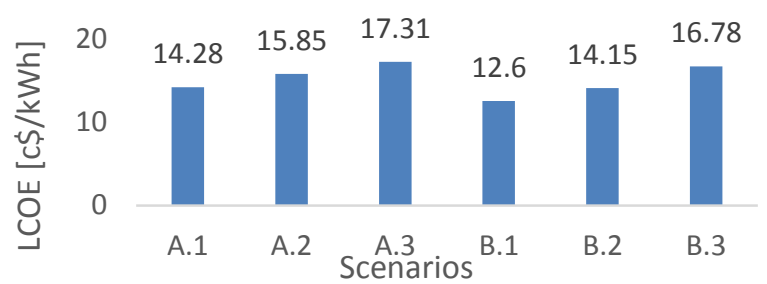

FIGURE 6. Levelized Cost of Electricity for all six scenarios. Scenario B.1 has the lowest value that is closed to the electricity price used for the calculations.

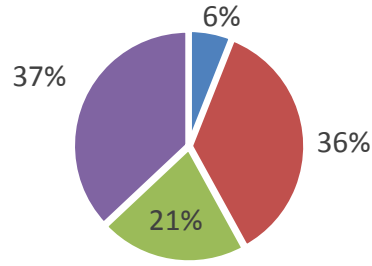

(a)

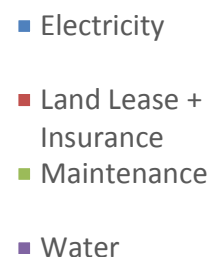

- Water

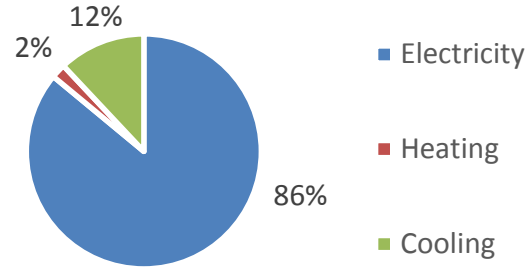

(b)

FIGURE 7. Yearly operating cost (a) and yearly revenues (b) for scenario B.1. The highest operating expense is the water purchased for the operation of the cooling tower and the majority of the revenues come from electricity sales.

Taking a closer look at the yearly operating expenses and income of scenario B.1 (Fig. 7), it is shown that the most cost intensive resource used by the power plant is water. Water is consumed by the wet cooling tower during its operation and it is an expensive resource in areas where it is scarce, as in Phoenix. In order to avoid this cost, a dry cooling tower can be used instead. However, this is expected to decrease the performance of the adsorption chiller significantly by lowering its $\mathrm{COP}$, when ambient temperatures are high (above $35^{\circ} \mathrm{C}$ ). This constitutes an interesting trade-off which requires further investigations.

The majority of the yearly income for the above scenario, $86 \%$, is linked to electricity sales. Another $12 \%$ is income from selling cooling services and a very small amount of $2 \%$ is linked to selling the heat directly to the households. This is justified by the fact that for $1 / 3$ of the year, there is no demand for the heat produced. In addition, the electricity selling price is also much higher (almost 4 times) than the selling prices of heating and cooling. The very small part of heating in sales is due to the location, as heating is only required for a limited amount of time during the year.

\section{CONCLUSION}

This study involves a physical system model of a HCPVT system as well as a thermo-economic analysis of a MW-scale trigeneration power plant in Phoenix, AZ, U.S.A. The transient simulations show a rapid temperature response of the system following a DNI increase. This leads to short heat-up times in the morning, thus longer heat production during the day. The control strategy pursued assures that the PV cells are not exposed to extreme temperatures above their operational limit, while the recuperated heat remains at a high temperature level $\left(85^{\circ} \mathrm{C}\right)$.

The thermo-economic analysis performed for six different scenarios shows that all of them are not profitable for the different configurations. However, the LCOE for the best performing scenario is very close to the retail electricity price used in the study. It is noteworthy that these results only consider partial utilization of the heat produced by the HCPVT systems, taking into account the low demand for space heating, the low COP of the adsorption chiller and the fact that there is no sale of cooling and heating during $1 / 3$ of the year. Additionally, there is a suboptimal coupling between supply and demand. In other words, an optimization procedure is needed to determine the optimal number of houses that the power plant serves. Furthermore, the electrical output can be increased by cooling the HCPVT systems at lower temperatures, when there is no demand of heat (free cooling). This will increase the efficiency of the PV cells, thus the electricity sales substantially. The selling price of cooling 
is a conservative assumption as well. Taking into account the fact that solar cooling reduces peak electricity demand, a higher effective price can be adapted to increase the yearly revenues.

Further operational and design approaches need to be investigated to quantify their promising potential towards profitability. A more profitable approach is to utilize a "smarter" storage control scheme and engage the back-up equipment in the production of chilled and hot water, thereby increasing the connected households ( 2 to 3 times) and the cooling and heating sales. Cold storage utilization shows promising potential as well, since it can decouple the production of chilled water from times, when the ambient temperature is highest. This decoupling will allow the utilization of dry cooling during the night at lower ambient temperatures, succeeding in water savings and higher COP for both chillers.

The HCPVT system is expected to outperform the results of this study economically and energetically when the utilization of the produced heat is maximized. Despite the suboptimal and indirect utilization of heat in the current study, the results show promising figures regarding economic performance. This leads to the conclusion that a better economic performance can be achieved through the optimized coupling of demand and supply for this application and through direct utilization of heat in other applications, such as industrial processes.

\section{ACKNOWLEDGMENTS}

This research was supported by the Commission for Technology and Innovation (CTI), Switzerland (KTI 14048.2 PFIW-IW). The authors thank Gianluca Ambrosetti for helpful discussions.

\section{REFERENCES}

1. "Photovoltaics Report", (Fraunhofer ISE, Freiburg, 2014).

2. S. P. Phillips and A.W. Bett, "Current status of Concentrator Photovoltaic (CPV) technology", (Fraunhofer ISE and NREL, Colorado, 2014).

3. F. Mauthner and W. Weiss, "Solar heat worldwide: markets and contribution to the energy supply 2012", (International Energy Agency - Solar Heating and Cooling Program, 2014).

4. "Technology Roadmap: Solar Heating and Cooling", (International Energy Agency, 2012).

5. CARNOT Blockset, Version 5.3, (Solar-Institut Jülich, Fachhochschule Aachen, Germany).

6. R. Bollinger, "Méthodologie de la synthése des systems énergétiques industriels", Ph.D thesis, Ecole Polytechnique Fédérale de Lausanne, 2010.

7. B. R. Burg, S. Paredes, T. Tick, W. Escher and B. Michel, "Receiver integrated cooling of high-concentrating photovoltaic thermal systems for efficient heat recovery, (submitted, 2014).

8. A. Selviaridis, "System modeling and thermo-economic analysis of a High Concentration Photovoltaic Thermal system", Master thesis, Ecole Polytechnique Fédérale de Lausanne, 2014.

9. F. Maréchal and B. Kalitventzeff, "Process integration: Selection of the optimal utility system", in Computers \& Chemical Engineering, 22, 149-156 (1998).

10. Polysun software, www.velasolaris.com

11. Meteonorm software, www.meteonorm.com

12. S. Fazlollahi, S. L. Bungener, P. Mandel, G. Becker and F. Maréchal, "Multi-objectives, multi-period optimization of district energy systems: I. Selection of typical operating periods", in Computers \& Chemical Engineering, 65, 54-66 (2014).

13. S. Fazlollahi, S. L. Bungener, P. Mandel, G. Becker and F. Maréchal, "Multi-objectives, multi-period optimization of district energy systems: II. Daily thermal storage", in Computers \& Chemical Engineering, 71, 648-662 (2014).

14. U.S. Energy Information Administration: Electric Power Monthly, www.eia.gov/electricity/monthly

15. U.S. Energy Information Administration: Natural Gas Prices, www.eia.gov/dnav/ng

16. City of Phoenix: Water and Sewer Rates and Charges, https://www.phoenix.gov/waterservices/customerservice

17. "Preisatlas: Ableitungen von Kostenfunktionen für Komponenten der rationellen Energienutzung", (Institut für Energie- und Umwelttechnik, Duisburg, 2002).

18. R. Turton, R. C. Bailie, W. B. Whiting and J. A. Shaeiwitz, Analysis, Synthesis and Design of Chemical Processes, (Prentice Hall, New Jersey, 2012). 